\title{
Chronic Arsenic Poisoning and Respiratory Effects in Bangladesh
}

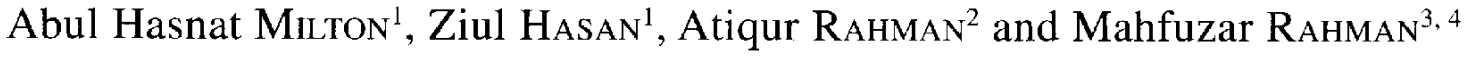 \\ ${ }^{1}$ Chief, Arsenic Cell, NGO Forum for Drinking Water Supply \& Sanitation, \\ ${ }^{2}$ Bangobandhu Sheikh Mojib Medical University, \\ ${ }^{3}$ Public Health Sciences Division, ICDDR'B: Centre for Health and Population Research, Dhaka, Bangladesh and \\ ${ }^{4}$ Division of Occupational \& Environmental Medicine, Faculty of Health Sciences, Linköping University, Sweden
}

\begin{abstract}
Chronic Arsenic Poisoning and Respiratory Effects in Bangladesh: Abul Hasnat MiLton, et al. Arsenic Cell, NGO Forum for Drinking Water Supply \& Sanitation, Bangladesh-A large population in Bangladesh have been exposed to naturally occurring inorganic arsenic through their drinking water. A prevalence comparison study of respiratory disorders among subjects with and without arsenic exposure through drinking water was conducted in Bangladesh. Characteristic skin lesions, keratoses and pigmentation alteration, and the water arsenic level confirmed the arsenic exposure. Three villages were selected from health awareness campaign programs. Participants in these courtyard meetings who had suspected skin lesions. i.e., keratosis, hyperpigmentation and hypopigmentation, were examined by a well-trained medical officer to confirm the diagnosis. Unexposed subjects were randomly selected from another village, where tubewells were not contaminated with arsenic. We interviewed and examined 218 individuals irrespective of age and sex from these villages. The arsenic level in their drinking water was measured and the mean arsenic level was $614 \mu \mathrm{g} / /$ (ranging from $136 \mu \mathrm{g} / /$ to $1,000 \mu \mathrm{g} / \mathrm{h}$. Information regarding respiratory system signs and symptoms was also collected. There were few smokers, and analyses were therefore confined to nonsmokers. The overall crude prevalence (or risk) among the exposed subjects for chronic cough, and chronic bronchitis, was three times the prevalence in the control population. Age was a slightly negative confounding factor. The crude prevalence ratios were noticeably increased for female participants compared to male participants. A possible explanation for this noticeably increased occurrence of respiratory signs and symptoms in women is related to the presence of weakness. These results add to the evidence that long-
\end{abstract}

Received Sept 14, 2000; Accepted Feb 5, 2007

Correspondence to: A.H. Milton, MBBS, M.Sc., Chief, Arsenic Cell, NGO Forum for Drinking Water Supply \& Sanitation, Dhaka, Bangladesh term ingestion of arsenic can cause respiratory problems especially among females.

(J Occup Health 2001; 43: 136-140)

Key words: Arsenic, Cross-sectional study, Drinking water, Respiratory disease, Skin lesion

Chronic arsenic intoxication from drinking water contaminated from geological sources has caused a devastating health crisis in Bangladesh ${ }^{1-4)}$. A similar situation can be observed not only in Bangladesh, but also in some other parts of the world. By the year 2000 , investigators estimated that between 35 and 77 million of the 125 million inhabitants were exposed to high inorganic arsenic levels through drinking water retrieved from tubewells ${ }^{5}$. The source of the arsenic is geologic, but controversy exists as to the mechanism whereby inorganic arsenic is mobilized and transported into the groundwater from the fine alluvial sediment of the Ganges delta.

Characteristic skin lesions (keratosis, hyperpigmentation and hypopigmentation) are the hallmark of high exposure to arsenic, and, nowadays, pose a public health problem in Bangladesh. These lesions may be used as an indicator of high exposure and are quite distinctive in contrast to other clinical manifestations of arsenic intoxication including weakness, conjunctival congestion, edema, portal hypertension, and hepatomegaly. These skin lesions generally develop five to ten years after exposure commences, although shorter latencies are possible. Emerging evidence shows that ingestion of inorganic arsenic may also lead to non-malignant respiratory effects. Limited epidemiological studies in Chile (not mentioned in other countries, i.e., Japan and Taiwan) have previously suggested an association between arsenic and nonmalignant respiratory effects ${ }^{6}$, and more recently another study from West Bengal, India has suggested that long term arsenic ingestion can cause pulmonary effects ${ }^{7}$.

In this paper we present respiratory system findings 
from a landmark epidemiological study that was conducted in Bangladesh, focusing on the prevalence of respiratory signs and symptoms which were assessed in the survey, including cough, chest sounds, and shortness of breath.

\section{Subjects and Methods}

\section{Data collection procedure}

Three 'Health awareness campaign' programs were organized through an NGO Forums for Drinking Water and Sanitation, in the three arsenic affected villages (according to the existing data, these villages were ranked as having high exposure) of Laxmipur, Barisal and Madaripur districts of Bangladesh. A courtyard meeting was organized in each village as part of arsenic mitigation activities, where arsenic related information was usually disseminated among the villagers. A well-trained medical officer, who confirmed the diagnosis and examined participants at these meetings, had suspected that skin lesions were due to arsenic ingestion i.e., keratosis, hyperpigmentation and hypopigmentation. A total of $\sim 150$ participants participated in these meetings. A total of 99 participants were included in this study and invited to participate, and the rest $(\mathrm{N}=51)$ were preliminarily excluded for being smokers or ex-smokers.

As there were no resources available for an extensive arsenic analysis program, it was impossible to clearly identify unexposed subjects in these villages. We therefore had to arbitrarily recruit unexposed individuals through door to door visit in three randomly selected villages in Nasirnagar thana. A total of 130 individuals were identified and invited to participate. The tubewells in Nasirnagar thana were known to be not contaminated with arsenic. A medical officer also examined all the individuals and their drinking water samples from the respective tube wells were also collected.

Details of participation were not recorded, but the response rate from those invited was excellent, with negligible refusals $(\mathrm{N}=10)$. An interview and brief medical examination were conducted for each participant. A total of 218 individuals (94 individuals exposed to arsenic, and 124 individuals unexposed) participated in the study. Drinking water samples presented by the diagnosed patients who were still drinking tubewell water were also collected. Few of the patients who were earlier diagnosed as arsenicosis patients stopped drinking water the arsenic contaminated tube wells and were now drinking from other arsenic free water sources such as arsenic free tubewells, rain water or surface water. We collected samples of water from the arsenic contaminated tube wells used by these patients. But we could not collect water samples from arsenic contaminated tube wells used by all the patients as some of the tube wells were either removed by the victims or out of order. A total of 39 water samples were collected and the arsenic concentration was measured by flow-injection hydride generation atomic absorption spectrometry (FI-HGAAS). The concentration ranged from $136 \mu \mathrm{g} / \mathrm{l}$ to 1,000 $\mu \mathrm{g} / l$.

\section{Interviews and clinical examinations}

Participants were briefly questioned about their sources of drinking water and socio-demographic characteristics by means of a questionnaire. Participants were asked to volunteer information about any health problems. If the participants did not volunteer any information concerning respiratory symptoms, an experienced physician then specifically asked them: Do you have problems with coughing? Do you have problems with shortness of breath? Auscultation focused on crepitation and rhonchi determined chest sounds.

Participants were also asked if they smoked now or in the past or had asthma and or tuberculosis. Participants who reported a smoking habit, clinical and past history of asthma or tuberculosis were excluded from consideration because of the relatively small numbers and potential confounding.

\section{Case definition}

A patient can be assumed to have chronic bronchitis if sputum has been coughed up on most days for at least three consecutive months for more than two successive years with the presence of rhonchi and/or crepitations.

A patient can be assumed to have a chronic cough if he/she has coughed on most days and has tightness and shortness of breath for at least three consecutive months for more than a year.

Asenical skin lesions were diagnosed in the presence of one or more of the following criteria: pigmentation changes in unexposed body surfaces and/or keratosis, especially on palms and soles. Melanosis may occur anywhere on the body, often showing rain-drop like pigmentation or diffuse dappling of dark brown, especially noticeable in nonexposed parts of the body. Leucomelanosis follows the same distribution and may be present even in the absence of melanosis. Keratosis is small, corn-like elevations, usually $0.4-1 \mathrm{~cm}$ in diameter and nodular, found on the lateral borders of palms, fingers and on the soles, heels and toes. Diffuse keratosis on the palms and soles could also be present. Melanosis and keratosis are the most prominent characteristic skin lesions in arsenic toxicity and may eventually progress into skin cancer. Physician interviewers were blind to the asrenic content in the drinking water of those subjects with diagnosed skin lesions.

\section{Statistical analyses}

The outcomes analyzed included participant-reported 
Table 1. Distribution of cases of chronic bronchitis and healthy subjects with regard to arsenic exposure along with crude prevalence ratios (CPR) and Mantel-Haenszel prevalence ratios (MH-PR) adjusted by sex

\begin{tabular}{|c|c|c|c|c|c|}
\hline \multirow{2}{*}{ Age } & & \multicolumn{2}{|c|}{ Men } & \multicolumn{2}{|c|}{ Women } \\
\hline & & Cases & Non-cases & Cases & Non-cases \\
\hline \multirow[t]{2}{*}{$5-25$} & Exposed & 2 & 11 & 3 & 12 \\
\hline & Nonexposed & 0 & 14 & 0 & 20 \\
\hline \multirow[t]{2}{*}{$26-50$} & Exposed & 9 & 11 & 12 & 25 \\
\hline & Nonexposed & 7 & 20 & 2 & 49 \\
\hline \multirow[t]{2}{*}{$>51$} & Exposed & 3 & 4 & 0 & 2 \\
\hline & Nonexposed & 4 & 5 & 0 & 3 \\
\hline \multirow[t]{2}{*}{ Total } & Exposed & 14 & 26 & 15 & 39 \\
\hline & Nonexposed & 11 & 39 & 2 & 72 \\
\hline \multicolumn{2}{|c|}{ Crude prevalence ratio (CPR) } & \multicolumn{2}{|c|}{1.6} & \multirow{2}{*}{\multicolumn{2}{|c|}{$\begin{array}{c}10.3 \\
(2.4-43.1)\end{array}$}} \\
\hline \multicolumn{2}{|c|}{$95 \% \mathrm{CI}$} & \multicolumn{2}{|c|}{$(0.8-3.1)$} & & \\
\hline \multicolumn{2}{|c|}{ Crude prevalence ratio (Total) } & \multicolumn{4}{|c|}{2.9} \\
\hline \multicolumn{2}{|l|}{$95 \% \mathrm{CI}$} & \multicolumn{4}{|c|}{$(1.6-5.4)$} \\
\hline \multirow{2}{*}{\multicolumn{2}{|c|}{$\begin{array}{l}\text { MH-PR } \\
95 \% \mathrm{CI}\end{array}$}} & \multicolumn{4}{|c|}{3.0} \\
\hline & & \multicolumn{4}{|c|}{$1.6-5.3$} \\
\hline
\end{tabular}

chronic cough, shortness of breath, chronic respiratory distress, intervals of rhonchi, or crepitation recorded by an experienced physician. All subjects having skin lesions, and a history of arsenic in drinking water were defined as exposed individuals. The participants were stratified as 5-25, 26-50 and more than $50 \mathrm{yr}$ of age. Crude prevalence ratios (CPR) and Mantel-Haenszel weighted prevalence ratios (MH-PRs) with $95 \%$ confidence intervals were calculated by means of the EpiInfo package ${ }^{8)}$.

\section{Results}

A total of 218 subjects participated in this study (for 94 exposed individuals exhibiting skin lesions, the sex ratio male: female was $1: 1.3$; for 124 unexposed individuals the sex ratio male: female was 1:1.5). As shown in Table 1 , the crude overall prevalence ratio (or risk) for chronic bronchitis in exposed subjects was 2.9 (95\% CI, 1.6-5.4). After adjusting for sex, the risk was slightly higher, as age exerted a negative influence, confounding for chronic bronchitis. The risk for chronic bronchitis was also analyzed separately for men and women. Interestingly, women had a six times higher risk than men, although all participants lived in the same environment.

The overall crude prevalence ratio for chronic cough was 2.9 (95\% CI 1.5-5.4). After adjusting for sex, the risk was almost the same, although women had a ten times higher risk than men (Table 2). The overall crude prevalence ratio for respiratory distress was twice as great in exposed participants as in unexposed, as shown in Table 3. Interestingly, exposed women had a five times higher risk of respiratory distress than men.

\section{Discussion}

This study provides evidence that ingestion of inorganic arsenic in drinking water results in pulmonary effects manifested by coughing, chest sounds in the lungs and shortness of breath.

The prevalence of each outcome occurred more frequently among the exposed subjects than among those unexposed to arsenic (Tables 1-3), and there was a higher risk for women, whether representing a true biological effect or a chance phenomenon remains unclear, however. A relationship between ingested arsenic and respiratory effects so far has only been reported in a limited number of studies from Chile ${ }^{6)}$, India ${ }^{7)}$, and now in Bangladesh. With other studies conducted in Bangladesh, women had also a slightly higher risk of developing hypertension, compared to men, but men usually work in the fields, and could be exposed to heat, dust and other external pollutants which might predict a higher prevalence of respiratory disease than in women.

Although the numbers were very small, and individual exposure data were lacking, the presence of respiratory effects was largely confined to those who had arseniccaused skin lesions. The mechanism is still unclear, but could be related to some underlying susceptibility to arsenic effects. In a recent study, a higher obstructive lung disease (COPD) mortality was shown in a population exposed to 
Table 2. Distribution of cases of chronic cough and healthy subjects with regard to arsenic exposure along with crude prevalence ratios (CPR) and Mantel-Haenszel prevalence ratios (MH-PR) adjusted by sex

\begin{tabular}{|c|c|c|c|c|c|}
\hline \multirow{2}{*}{ Age } & & \multicolumn{2}{|c|}{ Men } & \multicolumn{2}{|c|}{ Women } \\
\hline & & Cases & Non-cases & Cases & Non-cases \\
\hline \multirow[t]{2}{*}{$5-25$} & Exposed & 3 & 10 & 2 & 13 \\
\hline & Nonexposed & 0 & 14 & 0 & 20 \\
\hline \multirow[t]{2}{*}{$26-50$} & Exposed & 8 & 12 & 10 & 27 \\
\hline & Nonexposed & 7 & 20 & 1 & 50 \\
\hline \multirow[t]{2}{*}{$>51$} & Exposed & 3 & 4 & 0 & 2 \\
\hline & Nonexposed & 4 & 5 & 0 & 3 \\
\hline \multirow[t]{2}{*}{ Total } & Exposed & 14 & 26 & 12 & 42 \\
\hline & Nonexposed & 11 & 39 & 1 & 73 \\
\hline \multicolumn{2}{|c|}{ Crude prevalence ratio (CPR) } & \multirow{2}{*}{\multicolumn{2}{|c|}{$\begin{array}{c}1.6 \\
(0.8-3.2)\end{array}$}} & \multirow{2}{*}{\multicolumn{2}{|c|}{$\begin{array}{c}16.4 \\
(2.2-122.7)\end{array}$}} \\
\hline \multicolumn{2}{|c|}{$95 \% \mathrm{CI}$} & & & & \\
\hline \multicolumn{2}{|c|}{ Crude prevalence ratio (Total) } & \multicolumn{4}{|c|}{2.9} \\
\hline \multicolumn{2}{|c|}{$95 \% \mathrm{CI}$} & \multicolumn{4}{|c|}{$(1.5-5.4)$} \\
\hline \multirow{2}{*}{\multicolumn{2}{|c|}{$\begin{array}{l}\text { MH-PR } \\
95 \% \text { CI }\end{array}$}} & \multicolumn{4}{|c|}{2.9} \\
\hline & & \multicolumn{4}{|c|}{$1.5-5.3$} \\
\hline
\end{tabular}

Table 3. Distribution of cases of chronic respiratory distress and healthy subjects with regard to arsenic exposure along with crude prevalence ratios (CPR) and Mantel-Haenszel prevalence ratios (MH-PR) adjusted by sex

\begin{tabular}{|c|c|c|c|c|c|}
\hline \multirow{2}{*}{ Age } & & \multicolumn{2}{|c|}{ Men } & \multicolumn{2}{|c|}{ Women } \\
\hline & & Cases & Non-cases & Cases & Non-cases \\
\hline \multirow[t]{2}{*}{$5-25$} & Exposed & 1 & 12 & 1 & 14 \\
\hline & Nonexposed & 0 & 14 & 0 & 20 \\
\hline \multirow[t]{2}{*}{$26-50$} & Exposed & 4 & 16 & 4 & 33 \\
\hline & Nonexposed & 4 & 23 & 1 & 50 \\
\hline \multirow[t]{2}{*}{$>51$} & Exposed & 3 & 4 & 0 & 2 \\
\hline & Nonexposed & 3 & 6 & 0 & 3 \\
\hline \multirow[t]{2}{*}{ Total } & Exposed & 8 & 32 & 5 & 49 \\
\hline & Nonexposed & 7 & 43 & 1 & 73 \\
\hline \multicolumn{2}{|c|}{ Crude prevalence ratio (CPR) } & \multicolumn{2}{|c|}{1.4} & \multirow{2}{*}{\multicolumn{2}{|c|}{$\begin{array}{c}6.8 \\
(0.8-57.0)\end{array}$}} \\
\hline \multicolumn{2}{|c|}{$95 \% \mathrm{CI}$} & \multicolumn{2}{|c|}{$(0.5-3.6)$} & & \\
\hline \multirow{2}{*}{\multicolumn{2}{|c|}{ Crude prevalence ratio (Total) }} & \multicolumn{4}{|c|}{2.1} \\
\hline & & \multicolumn{4}{|c|}{$(0.9-5.0)$} \\
\hline \multicolumn{2}{|c|}{$\begin{array}{l}\text { MH-PR } \\
95 \% \text { CI }\end{array}$} & \multicolumn{4}{|c|}{2.1} \\
\hline \multicolumn{2}{|c|}{$95 \%$ CI } & \multicolumn{4}{|c|}{$(0.9-4.8)$} \\
\hline
\end{tabular}

arsenic in Chile ${ }^{9)}$. Information about the relationship between ingested arsenic and non-malignant respiratory effects has so far only been reported from Chile but now also in Bangladesh. Studies from arsenic-affected regions in Taiwan, Chile and Argentina have shown an increase in lung cancer mortality ${ }^{10)}$. It is of interest to note that many established lung carcinogens also cause non-malignant lung disease, including smoking, asbestos and silica. The surprising characteristic of arsenic is that it seems to increase both malignant and non-malignant respiratory diseases after ingestion. The toxicology of the pulmonary effects of inorganic arsenic is not known, but arsenic can 
accumulate in human lung tissue.

The main limitations of the current investigation involve study design, especially the unsystematic sampling of water supplies in the study area, lack of information on the amount of water consumed and the small study numbers. Furthermore, although chronic cough and coughed sputum is a major cause of tuberculosis in Bangladesh, it would nevertheless have been desirable to identify such patients among chronic respiratory disease patients, and subject those with chronic cough and sputum to microscopic examination, but this was not economically possible, however. Some observer bias might have occurred during interviews and clinical examination of patients with skin lesions, in so far as the observer could have had some idea of the exposure status of the subjects but not their level of exposure. A self selection bias may occur, or alternatively, some undetected selection phenomenon might be responsible or there was weakness.

There is a lack of similar findings from other countries such as Japan and Taiwan, but a few occupational studies conducted in the 1950s in Sweden have also reported non-malignant respiratory effects in copper smelter workers exposed to airborne arsenic ${ }^{\text {(2) }}$. Information on smoking habits was not presented in this Swedish study, which might have contributed to the reported signs and symptoms. Nonetheless, the strength of the current findings in terms of the very high prevalence ratios, along with the plausibility of finding non-malignant respiratory effects based on studies in Chile, and now recently in West Bengal, India, suggest that non-malignant respiratory effects may indeed result from ingestion of inorganic arsenic, and are much stronger in female participants.

Acknowledgment: The authors would like to thanks Dr. Dipankar Chakraborti, Jadavpur University, Calcutta, India, for analyzing the water arsenic levels; and Professor Olav Axelson, Division of Occupational and Environmental Medicine, Faculty of Health Sciences, Linköping University, Sweden, for comments on this manuscript.

\section{References}

1) Rahman M, Tondel M, Ahmad SA, Axelson $O$. Diabetes mellitus associated with arseni exposure in Bangladesh. Am J Epidemiol 1998; 148: 189-203.

2) Rahman M, Tondel M, Chowdhury IA, Faruquee $\mathrm{MH}$, Ahmad SA, Axelson O. Hypertension and arsenic exposure in Bangladesh. Hypertension 1999; $33: 74$ 78.

3) Tondel M, Rahman M, Magnuson A, Chowdhury IA, Faruquee MH, Ahmad SA. The relationship of arsenic levels in drinking water and the prevalence rate of skin lesions in Bangladesh. Environ Health Perspect 1999; 107: 727-729.

4) Rahman M, Tondel M, Chowdhury IA, Axelson O. Relation between arsenic exposure, skin lesions and glucosuria. Occup Environ Med 1999; 56: 277-281.

5) Chowdhury UK, Biswas BK, Chowdhury TR, et al. Groundwater arsenic contamination in Bangladesh and West Bengal, India. Environ Health Perspect. 2000 May; 108: 393-397.

6) Zaldivar R, Ghai GL. Clinical epidemiological studies on endemic chronic arsenic poisoning in children and adults, including observation on children with highand low- intake of dietary arsenic. Zentrabl Bakterio. I Abt Originale B: Hygiene, Kraamkenhaushygiene, Betriebshygiene, Praventive Mediczin Medizin 1980; 170: 409-421.

7) Guha Mazumder DN, Haque R, Ghosh N, Dey BK, Santra A, Chakraborti D, Smith AH. Arsenic in drinking water and the prevalence of respiratory effects in West Bengal, India International Journal of Epidemiology 2000; 29: 1047-1052.

8) Dean JA, Dean AG, Burton A. EPI INFO. Atlanta (GA): Centers for Disease Control; 1988.

9) Smith AH, Goycolea M, Haque R, Biggs ML. Marked increase bladder and lung cancer mortality in a region of Northern Chile due to arsenic in drinking water. Am J Epidemiol 1998; 147: 660-669.

10) World Health Organization. Environmental health criteria 18: Arsenic. Geneva: World Health Organization; 1981.

11) Guha Mazumder DN, Das Gupta J, Santra A. Noncancer effects of chronic arsenicosis with special reference to liver damage. In: Abernathy $\mathrm{CO}$, Calderon RL, Chappel WR, ed. Arsenic: exposure and health effects. London: Capman and Hall; 1997: 112-123.

12) Gerhardsson L, Brune D, Nordberg GF, Wester PO. Multielemental assay of tissues of deceased smelter workers and controls. Sci Tot environ 1988; 74: 97110. 